\title{
Universal simplicity? The alleged simplicity of Universal Credit from administrative and claimant perspectives.
}

\section{Introduction}

Simplicity is a central tenet that has been used to explain and justify the design of Universal Credit and is recognised by those inside and outside of government alike as a positive feature of the policy. There has been surprising staying power in the idea that a positive (or redeeming) feature of Universal Credit is its simplicity. However, we aim to highlight that clarification is needed as to what is meant by simplicity and crucially, who the new system will be simple for. Our argument has application both for Universal Credit specifically, and more broadly to simplicity as a feature of social security policy design.

In this article we draw on evidence from two empirical qualitative studies. We argue that while from a policy design perspective, Universal Credit could appear simple, this is challenged by lived experience data that is oriented towards accessing the experiences and perspectives of claimants. In fact, rather than eliminating complexity, Universal Credit risks shifting it onto the shoulders of claimants themselves.

The article is divided into three main sections. The first sets out the case made for simplicity within Universal Credit, examining policy documents to establish what may be meant explicitly and implicitly by the term. The second further explores the meaning of simplicity by distinguishing between two forms: administrative and claimant simplicity. The third presents empirical findings to consider simplicity from the perspective of claimants in some specific areas.

\section{The introduction of Universal Credit - simplicity as a central tenet}

Claims of simplicity have been crucial to the design, development and advocacy of Universal Credit and can be seen in government and policy documents as well as in the words of those tasked with its ongoing implementation. This section will examine the origin of these claims and their meaning.

The recognition of the complexity of the current system and a desire to simplify it predates the introduction of Universal Credit. In 2007, the Work and Pensions Committee identified a need for radical reform of the UK benefits system and what they called its "dysfunctional complexity", concluding that "simplification should be a key priority for the DWP" (Work and Pensions Committee, 2007, 5). One idea put forward was the creation of "a single working age benefit" (Work and Pensions Committee, 2007, 7).

This idea was extensively developed in work by the think tank the Centre for Social Justice and set out in their report 'dynamic benefits, towards welfare that works' (2009). In it, they identify three main failings of the benefits system of the time: it disincentivised work through high withdrawal rates, it penalised desirable behaviour through interacting benefit rules and it was very complex, leading to high costs of delivery and "reinforcing dependency" $(2009,17)$. The proposed solutions in response to these failings were related to behavioural change and involved a conviction that 
human behaviour could be understood and influenced through income gains and penalties, particularly to incentivise paid work (Wright, 2012, 322), to adopt "desirable behaviour" such as marriage and home ownership and to ultimately move away from benefit receipt altogether.

Simplification of the system was seen as a central means to achieving these solutions. Within such a complex system, so the argument goes, claimants are baffled into inertia and unable to bear the risks of changing their lives in positive ways (taking a job, saving money, moving in with a partner, buying a house, etc.). In more immediate terms, claimants found difficulty reporting changes of circumstance to multiple government agencies and faced the adverse consequences of inaccurate, delayed and changeable payments (Centre for Social Justice, 2009; Hills et al, 2006).

Merging or grouping existing benefits was seen by the Centre for Social Justice as a key simplification tool to address the failings they had identified. Namely through the introduction of a dual benefit system to replace "the current 51 possible benefits" with "two streamlined payments - Universal Work Credit and Universal Life Credit" (2009, 25). The former would combine Job Seekers Allowance, Income Support, Incapacity Benefit/Employment and Support Allowance and the latter Housing Benefit, Council Tax Benefit, Disability Living Allowance, Working Tax Credit and Child Tax Credits $(2009,47)$. This would mean bringing together benefits with complex existing entitlements and administrative structures but which were also devised to cover very different contingencies and circumstances. At this stage in its development, the persuasive nature of Universal Credit as a solution to complexity was very much centred around its ability to take multiple benefits and combine them into one.

The idea of simplification was carried forward into the current version of Universal Credit which brings together six means-tested benefits for people of working age into a single monthly payment that is adjusted monthly using real times earnings information (RTI) and delivered by a single government agency (DWP). In his Foreword to the government white paper of 2010, 'Universal Credit, Welfare that Works', Ian Duncan Smith stated that "at its heart, Universal Credit is very simple" (DWP, 2010) and linked this simplicity to several concrete aims:

- To make it clear that work pays in order to reduce the risks associated with movements into work;

- to clarify the application process so that people knew what they would be entitled to, to improve take-up rates;

0 to respond better to earnings change and avoid issues at the end of the tax year (such as happened under Tax Credits);

- to reduce fraud and error;

- to provide clarity on the consequences of non-compliance for claimants;

$\circ$ and to move people out of poverty.

Simplification remains a central rationale in more recent policy documents. In the Foreword to the 2015 update on progress and delivery, 'Universal Credit at Work' it was reaffirmed that the new benefit was, "changing the dynamics in the system, making things simpler, and ensuring work pays" (DWP, 2015, 5). In the "Universal 
Credit Full Business Case Summary' (DWP, 2018c), 'simplicity' is operationalised as the main component of 'non-financial incentives' that led to claimants choosing to work or to work more. 'Simplicity and transparency' is identified as one of the five foundational 'policy levers' of Universal Credit in the government's Theory of Change (DWP, 2017, 81). As aspects of Universal Credit have been refined or reformulated throughout the roll-out process, the central notion of simplicity has remained both as a stand-alone principle of good policy design and as instrumental to other policy goals.

In these examples simplicity is constructed as good for both intrinsic and extrinsic reasons, driving positive change within the system. In short: 1) a simple system is an inherently good system, and 2) a simple system will lead to other policy goals being achieved. Simplicity is deployed as shorthand for what is good about Universal Credit, and as a central component underpinning almost a decade of continuing welfare reform.

\section{The meaning of simplicity}

Simplicity has a powerful intuitive value. The intrinsic appeal of simplicity as a good and desirable aim by policymakers can be thought of as a sort of common sense. There has been an assumed consensus that the social security system in particular is far too complex (Work and Pensions Committee, 2007). As a result, working-age social security policy is formulated in a way that is not specific in defining simplicity, and does not distinguish between different types of simplicity and their potentially contradictory nature. This is not to suggest that there are not aspects of the legacy system that are complex (see for example, Millar, 2003) with negative implications, or that it is not possible to identify specifically where complexity and simplicity lie in social security design (Harris, 2015, 201-213). Moreover, policymaking often fails to more carefully consider and disaggregate what is meant by simplicity as a desirable feature of policy design.

This section will first consider simplicity's 'common sense' nature before developing Millar's (2005) framework with a focus on administrative and claimant simplicity (although it forms part of Millar's framework, simplicity from the perspective of the public is not our focus here).

\section{Simplicity as policy common sense}

We suggest that 'simplicity' can be thought about as an example of what can be called policymaker common sense. By common sense we mean features of policy design that are widely accepted as good or correct without there needing to be an explicit explanation as to why this is. Simplicity is constructed as an intuitively and obviously good tenet of social security design. Albeit simplicity is also connected with various positive outcomes in policy documents, most notably labour market participation, it is also presented as an overarching a priori rationale for Universal Credit's design. The architects of Universal Credit characterised complexity as a longstanding problem that needed to be addressed (Centre for Social Justice, 2009; DWP, 2010). Exactly what is meant by simplicity does not need to be explained further, because there is a shared understanding that it is obviously a good thing to aim for. 
Indeed, simplicity has intuitive appeal in academic and third sector spheres as well. A common position on Universal Credit by organisations or individuals campaigning for reform is that the principles behind the policy are sound and that the issues lie in design detail and implementation (Finch et al, 2014; Citizens Advice, 2015).

For example, the statement "we support the aims and principles of Universal Credit to simplify the benefits system" is found in different forms in recent Citizens Advice policy documents, which then go on to discuss design and implementation (Citizens Advice $2017 ; 2018 ; 2019,3)$. The implication here is that if their design and implementation suggestions were accepted, a 'simple' system would be achieved. However, rather than being a straightforwardly good aim, we argue that simplicity depends on perspective. Simplicity as currently construed often elides its multiple possible meanings, offering a neutral language and point of agreement that facilitates discussion between third sector actors and government, but which can inadvertently fail to acknowledge claimants' perspectives.

This predilection for simplicity fits with underlying assumptions of policy design. We want to suggest that this relates to the enduring prizing and prioritisation of positivist, quantifiable forms of evidence in policy design (for further nuance see, Monaghan and Ingold, 2019). This relates to 'hierarchies of evidence' (Parkhurst, 2017, 29), which rest on a (post)positivist epistemological orientation, where methodological approaches are ranked by their ability to eliminate 'bias'. Furthermore, a characteristic of a (post)positivist approach is the pursuit of parsimonious explanation (Williams, 2003). Qualitative approaches with interpretivist underpinnings fall to the bottom, or are outside of, such a hierarchy.

Looking to social security policy's neighbour, tax policy design, simplicity is a wellestablished explicit principle. The Mirrlees Review states the intuitive good of simplicity in tax design, saying that, "It is often said that a good tax system should be a simple one. And surely a simple one is better than a more complex one if it achieves the same ends." (Mirrlees et al, 2011, 42). One also sees this in the centring of quantifiable metrics in social security policymaking. Evaluations of Universal Credit do tend to combine quantitative and qualitative evidence (see, for example DWP, 2017; DWP, $2018 b)$, but this is within an overarching logic where the outcomes of interest are measures such as increasing hours or earnings (DWP, 2017, 81). An appreciation that the social world is messy and incredibly complex, is often more closely allied to interpretivist approaches and qualitative evidence. The predominant view would be that we should aim to abstract away from this messiness. However, some types of evidence and insights are lost in doing so, as we aim to demonstrate in this article. It is not instructive to position simplicity as a self-evident good.

As will be shown, complexity in relation to many aspects of Universal Credit is unavoidable (Millar, 2005; Royston, 2017), and what is meant by simplicity needs to be specified. The 'legacy' social security system has developed in part out of attempts to provide a safety net, encourage certain behaviours and meet complex needs (Spicker, 2017). By aiming to 'streamline' or simplify the working-age social security system without clearly stating what is meant by simplicity risks either concealing complexity (Harris, 2015, 221) or shifting it elsewhere.

To help us structure our understanding about simplicity, we build on the distinctions set out by Millar (2005). Millar's account highlights the importance of defining and 
distinguishing between types of simplicity according to the perspective of administration; applicants; and the wider public. Millar outlines that administrative simplicity involves fewer rules and/or fewer benefits; applicant simplicity involves a benefit system that is easy to access and understand; and simplicity for the public involves clear messages about what social security benefits are for and what the rights and responsibilities of claimants are. Millar notes that these different perspectives might sometimes be in conflict with one another, and a challenge is to balance and prioritise them. In this article, we aim to explore the import of distinguishing between claimant and administrative simplicity. By defining simplicity more specifically by accounting for perspective, we suggest that a further challenge to policymakers is a misapprehension of what constitutes claimant simplicity.

\section{Administrative simplicity}

Much of the simplicity underpinning Universal Credit can be defined as administrative simplicity, although it is not explicitly identified as such by policymakers. In turn the claim is made that this form of simplicity will be positive for recipients. Universal Credit has been designed to create one system rather than multiple systems, something Neil Couling, the director general of Universal Credit, has described as:

"a huge challenge that is only feasible if the rules are kept simple. That has been achieved by adopting some core principles into the design of the system to guide the creation of simple and clear sub-policies and processes." (Couling, 2018, E5)

Within administrative simplicity we can distinguish between administrative technologies and systems, and frontline delivery.

Universal Credit is an attempt to achieve administrative simplicity by bringing together six means-tested benefits ${ }^{1}$ that are currently administered by different local and national government departments each with its own rules and administration. For example, Job Seekers Allowance is a benefit for people who are available for work, Employment and Support Allowance for those who have limited capability for work and Working Tax Credits is paid to those who are in work and on a low income. Other benefits such as Carers Allowance and Council Tax Support remain outside the Universal Credit system.

A centralised system also allows administrative simplicity to be achieved through digital means. Universal Credit is innovative in that the system is linked to the Revenue's real time earnings system (RTI), meaning that entitlement is calculated according to live earnings data, and not 'manually'. Linking and automating the RTI system for Universal Credit administration has infamously been hugely complex and expensive to set up (NAO, 2018). Universal Credit's processes are 'digital by default'; for the first time the primary way in which communication takes place between the government and claimants is online. Claims are made and sustained using an online Universal Credit portal. The aim is to achieve frontline simplicity through further automation, which, it is assumed, also achieves simplicity for claimants.

\footnotetext{
1 Income based Job Seekers Allowance, Income related Employment and Support Allowance, Income Support, Housing Benefit, Child Tax Credit and Working Tax Credit.
} 
As a result of the linkage to the RTI system to assess entitlement, and because of normative claims that monthly social security receipt reflects and encourages claimants to adapt to 'the world of work', Universal Credit is assessed and paid on a monthly basis in arrears (DWP, 2019). To receive their initial claim, recipients must wait five weeks (with the extra week added for administrative purposes). Further, one payment per household is made, as opposed to the legacy social security system where a patchwork of payments might be received by different members of a couple (DWP, 2019). All of this, in theory, promises a straightforward system that can be applied and administered consistently.

\section{Claimant simplicity}

The administrative view of simplicity set out above dominates policy debate. Claimant simplicity might be achieved through administrative simplicity in these accounts. In many ways this focus on administrative simplicity is inevitable. The apparatus of government scrutiny means that judgements are often on the basis of how money is used efficiently or saved (Treasury, 2018), which can be achieved by reforming administrative processes. As shown above, there is an emphasis on quantifiable outcome measures for the evaluation of Universal Credit. Space is diminished whereby the experience of claimants might form a central focus.

Another perspective is therefore often missing, that of the claimant themselves. What we have termed administrative simplicity does not necessarily lead to, or equate with, simplicity from the perspective of claimants. The way in which simplicity is currently presented does not allow for this sort of nuance or distinction. Might it actually be, for example, that greater administrative simplicity leads to less claimant simplicity? We suggest that lived experience data is crucial to understand the functioning of policy, and in this specific context allows us to disaggregate the meaning and implications of so-called simplicity.

Royston (2017) argues strongly that the complexity of the benefits system is here to stay but that claimants should be shielded from this complexity. Using the analogy of a complex electricity supply and flicking a light switch, he argues that users of the social security system should be able to access it with ease without the need to fully understand it. Any simplification, he argues, must come from the "user's perspective" and he sets out a series of questions that simplifications should address. Among these is "Does the change make it easier for the claimant to make 'real world' decisions?" $(2017,343)$.

\section{Claimants' experience of simplicity}

In order to develop Millar's (2005) distinction between 'simple to administer' and 'simple for the applicant to access and understand', we will now look at how specific characteristics of Universal Credit, which can be understood as enacting simplicity from an administrative perspective, are experienced from the perspective of claimants. This claimant experience of simplicity, we argue, is often not fully appreciated in policy decision making and discussion.

This section will therefore draw on our own qualitative evidence to explore and illustrate to what extent simplicity is achieved from a claimant perspective. The first 
sub-section will introduce our work and methods and the subsequent sections will look at aspects of administrative simplicity and consider how these relate to simplicity from our claimants' perspectives. We consider some of the 'headline' features of Universal Credit: first, monthly assessments, second, monthly payments and third, lump sum payments.

\section{Introduction to our work and methods}

The first study was carried out between 2015 and 2018 and comprised qualitative interviews with 43 working-age means-tested social security recipients living in London. Almost all participants were in receipt of 'legacy benefits' that would in time be replaced by Universal Credit, and two were in receipt of Universal Credit. 27 of the participants were unemployed. Most lived in rented accommodation, and 21 had resident children. The focus of the wider study was on how money in the form of social security benefits was experienced and used by its recipients.

The second study was carried out between 2017 and 2019 and involved qualitative interviews with means-tested benefit claiming households over a three-four-month period. Participants were also asked to fill in income and expenditure diaries. Recruitment of a mixed sample of 15 households took place in a small city in the UK. All participants were of working age, ten had dependent children and most rented their accommodation. Ten had income from earnings and all claimed at least one meanstested benefit, 13 claimed Universal Credit. The focus of the overall study was the experience and management of short -term income change.

It was deemed fruitful to combine these two sources of qualitative data. There is a growing recognition that there is benefit in combining qualitative data sources, in order to pursue a fuller picture of phenomena of interest, which can only be accessed incrementally when using small scale qualitative approaches. The accounts of our participants allow us to work towards an interpretation of the 'shared typical' (Mcintosh and Wright, 2019, 460). It is not the aim of qualitative research to be generalisable in a statistical sense, but we understand the aggregation of these two studies as 'second order construction', whereby we are specifically interested in commonality and complementarity and therefore the 'bigger picture' behind the 'islands of knowledge' of single studies (Wright and Patrick, 2019, 601). Further, the studies are apt to combine because they provide coverage of both the legacy and UC systems, while both being underpinned by a focus on money management practices.

There is also an ethical impetus to make as full use as possible of data that participants have drawn on various resources (time, energy, emotion, etc) to generate. In addition, the use of qualitative data allows us to access micro aspects of how money is used and experienced in people's daily lives, thus allowing us to explore an important but often overlooked aspect of social security policy design.

Ethical approval was obtained from the relevant university ethics committees, participants gave informed consent to take part anonymously and pseudonyms will be used in this article.

Both studies were analysed using thematic analysis, carried out using QSR NVivo software, and taking a primarily inductive data-driven approach (Boyatzis, 1998). The 
specific analysis from this article began from an interpretation of simplicity as manifested in policy documents, which is summarised in the preceding sections. This led to the identification of aspects of policy design declared to be simple, which we then in turn held up against the corresponding thematic codes and themes in our data to consider whether the notion of simplicity also captured what was being expressed from the perspectives of our participants. We then worked iteratively to compare and incorporate the two studies, which led to us developing and refining our understanding of simplicity as defined by perspective.

In the findings section below we present cases from our data that best illuminate this tension between administrative and claimant simplicity, and also that illustrate findings that were patterned across the data (i.e. not extreme or outlier cases).

\section{Monthly assessment}

Monthly assessment in arrears is a defining characteristic of Universal Credit and its simplified administrative processes using Real Time Information (RTI). From the initial claim date, a monthly assessment period is fixed in which earnings, other income and circumstances are assessed. For example, if a claim is made on $20^{\text {th }}$ January, a monthly assessment period will be set from $20^{\text {th }}$ January to $19^{\text {th }}$ February and is followed by a seven day period to process payments (DWP, 2019). This means a fiveweek wait is built into the system with a rigid assessment period. Both of these design features can provide challenges for claimants.

While inseparable from the design features achieving administrative simplicity, there is increasing evidence that waiting five weeks for a first payment can cause severe hardship (The Trussell Trust, 2019). Within study two, the initial waiting period was experienced by participants as a period of income inadequacy which required the borrowing of money from different sources if available, or going without. Those moving from full-time monthly paid employment fared better, as did those with secure relational networks, but all were addressing a lack of income (see also Pemberton et al, 2017). Here, administrative simplicity comes at the expense of claimants' financial security.

The fixed nature of the monthly assessment period also poses challenges to claimants, making the date on which a change happens or is reported to have happened vital to how much Universal Credit is paid. For example, if a change is reported just before an assessment period ends, it is taken into account in the following month's pay, if it is reported after then an increase or decrease in payment won't occur until the month after, with no backdating (Tucker and Norris, 2018). The government has acknowledged that there may also be issues for people who are paid more frequently than monthly who may receive more than one month's worth of pay packets in an assessment period ${ }^{2}$ and has provided a guidance document so that claimants can work out when they will be over or under paid Universal Credit as a result of this feature (DWP, 2018a, see Figure 1). The advice constructs the onus as being on the claimant to deal with fluctuations of income.

\footnotetext{
${ }^{2}$ For example, those who are paid 4-weekly have one month a year where they receive two pay packets.
} 


\section{<Insert Figure 1 here>}

The claimant experience of monthly assessments in study two partly depended on the stability and payment frequency of income. For those who experienced change, the monthly assessment period was experienced as inflexible and financially destabilising which again required effort to pursue and establish other forms of security to compensate. One participant, Sue, lived in a housing association rented flat with her partner and two children. During the four-month research period, she was on maternity leave from a part-time clerical job and received her maternity pay on the same date each month. Sue explained how she experienced their monthly assessment period, saying:

"Our assessment period was from $30^{\text {th }}$ November to $29^{\text {th }}$ December. I get paid on the last working Thursday of every month so the $30^{\text {th }}$ was a payday for me and then I got paid on $28^{\text {th }}$ so they deemed that I got paid $£ 1400$ [in one month] well nearly $£ 1500$ when actually I only got paid $£ 790$ so they combined my two months wage"

As a result, this family went without their Universal Credit payment and had to borrow money from Sue's mother over the Christmas period. Here, the assessment structures deemed to achieve administrative simplicity can be completely misaligned with the income structures as experienced by claimants, for which they then must compensate.

\section{Monthly payments}

Monthly payments are also an important part of the administrative simplicity of Universal Credit. Alongside an attempt to mirror monthly paid work there are administrative simplification advantages to a monthly payment schedule, which stem from the Real Time Information system (RTI). However, around 50 per cent of those on the lowest incomes are paid weekly (DWP, 2011) and 'legacy benefits' are received weekly, two-weekly or four weekly. ${ }^{3}$ How simple will monthly payments be for people who are used to other patterns of income from work and social security benefits and who have developed corresponding budgeting processes? In both studies, the organisation of money within households most often revolved around a short-term system of days and weeks.

In study two, monthly payments were experienced differently depending on the receipt of other income and previous experience of monthly receipt. Monthly payments could fit well with monthly bills and for those used to monthly wages, but others found the move from weekly, two weekly and four weekly pay under the legacy system to monthly pay a challenge. One participant, Katy, who lived in a flat rented from a local housing association with her two children, refers to the long period in which she had received weekly money:

"Nearly half my life, you know getting paid weekly and going to monthly it was difficult, and they don't give you any help like, apparently there is some kind of

\footnotetext{
${ }^{3}$ Claimants can also exercise choice over whether they receive Child Benefit and Tax Credits in weekly or four weekly payment cycles.
} 

offered that."

Katy also refers to the solution put forward by the government of budgeting advice but says she wasn't offered it. ${ }^{4}$ Whether or not behaviour change, such as the adoption of monthly budgeting, happens over the long term, this administrative simplicity conflicts with Katy's current and historical experience. Here, administrative simplicity imposes a monthly payment pattern on those who had previously received weekly money challenging well established money management practices. For Katy, this had previously meant shorter periods of going without money or "never having to go long" before her next payment.

In study one, where almost all participants were in receipt of legacy social security benefits, the majority of participants spoke about using their money in terms of days and weeks. A small number of participants (seven out of 43 participants) were oriented towards slightly longer-term timescales, encompassing weeks and months. The appeal of operating longer term involved having better oversight of one's finances, and 'knowing what you've got to play with'. This minority of participants tended to be in receipt of working tax credits, and therefore had slightly higher household incomes than those out-of-work (and also had the option to opt to receive tax credits four weekly or weekly). For the majority of participants, however, short term timescales were instead crucial for successful money management.

In study one, when asked about their organisation of money, the majority (36 out of 43 participants) described strategies of short-termism that involved daily and weekly management. Three main notions underpinned and explained this short termism. The first was the ability to establish a degree of security by managing and planning within short-term horizons. Rachel, for example, explained that with her tax credits, "I've got it [paid] weekly and I know what I'm doing with it". Sabrina explained that her weekly Child Benefit payment was a reassuring source of security, "because I...think, 'right I've got that 20 pound, if I needed it for anything'." The second notion was that shorttermism was a matter of survival. Turner was frank that when you are "budgeting pennies", your financial situation is a "concoction of desperate moves". For some participants, especially those who were currently unemployed, two weeks was too long and some described borrowing money from family and friends before their next social security payment arrived. The third notion, and a function of the previous two, was that money was therefore highly transient. As Kirsten remarked, money "just goes", it "disappears".

Study two found similar short-term money management patterns within the sample. When asked how frequently they budgeted, weekly budgeting periods were adopted by seven households, two-weekly budgeting periods by four households, and monthly budgeting periods by four households. Short-termism was linked to attempts to control unstable and inadequate income and often corresponded with the short-term receipt

\footnotetext{
${ }^{4}$ Although some participants expressed that budgeting advice was pointless either because they were the ones who already knew how best to make the most of their current financial situation, or that the notion of budgeting was inappropriate. As Sarah from study one explained, "I say it's not about budgeting because the income is quite small, very, very small".
} 
of income. Conversely, a preference for monthly budgeting corresponded with receiving income monthly and the habit of matching it to regular monthly bills.

Short-termism in the context of means-tested social security receipt can be understood as a crucial dynamic and tool for managing one's income, which is particularly acutely pronounced for the payment levels provided by out-of-work benefits (Davis et al, 2018). Short-termism here is a strategy of achieving a degree of control over one's finances (Daly and Kelly 2015, 48; Shildrick et al, 2012, 169-174). These experiences are in direct opposition to the claims of administrative simplicity and related claimant simplicity cited in the monthly payment design of Universal Credit.

\section{Lump-sum payments}

As well as the change in frequency of payments, Universal Credit lumps together several previous payments into one and pays it directly to claimants. A claimant of legacy benefits for example could have received Housing Benefit paid directly to their landlord if they were living in social housing, weekly Child Benefit, two weekly Employment and Support Allowance and four-weekly Child Tax Credit and would now, under Universal Credit, be paid one sum from one government agency.

There has been growing recognition that people divide up and 'earmark' their monies for specific purposes, going against assumptions of standard economic theory (Zelizer, 2017; Sykes et al, 2014). Study one found that participants engaged in complex earmarking practices to separate out their monies, allocate, and protect different amounts for different purposes. The 'pay days' of different benefit payments acted as crucial organisational markers. Further, different bank accounts or the physical separating out of cash was used to enforce distinctions between monies. Rohina, for example, described how she used her patchwork of payments across short time timescales. Her account demonstrates both how earmarking and distinctions between monies allowed her to meet her most pressing outgoings, but also how difficult this is given the low level of her income:

"So basically, every Tuesday I get paid the Child Tax Credit, and that would go into my other account, and that's the only money I use to live on. That's the only money, the rest will go on bills, that is the only cash available to me, but that account is always overdrawn, always overdrawn, because it's not enough. So when it comes in, 50 of that goes to cover the overdraft, do you see what I mean. So l'm always short. Sometimes all of it goes, and sometimes it's even not enough, do you know what I mean. So that money is shopping money, so some, I haven't done shopping for months. And the kids have sort of said to me, "Mum why don't why don't we do shopping any more", I say because we have no money. So what I do is I just buy cheap things, like tins and things. Like we eat, don't get me wrong, we eat, I did consider going to the foodbank.... So I haven't done shopping like that for, like I say, at least 6, 7 months. I just buy when I need now, because that's all I can do."

Rohina separates out her Child Tax Credit, her 'Tuesday money' into another bank account, physically sectioning it off in order to designate it as money to cover her living costs. Although as she notes, this account is often overdrawn, her strategy is systematically undermined and this money does not suffice to do 'proper' shopping. 
Study two highlights the importance of varied pay dates and relational coping strategies compromised by the lumping together of payments under Universal Credit. Participants relied on informal systems of saving and borrowing by arranging their outgoings in relation to the pay dates of friends and family. Robert, who lived alone and had multiple health conditions would regularly borrow money from a friend, with the understanding that they would get the money back the next week when he received his benefits:

"I've got a friend that gets paid next Wednesday and she usually lends me a bit of money and then I pay her back when I get my PIPs on the Thursday following."

This strategy of smoothing low and changeable income was also adopted by other participants in studies one and two in different ways such as shopping for a friend just after being paid and expecting it back on their pay date. This draws attention to the importance of informal networks in coping with low and changeable income. Families and friends can provide financial services that are not available from other sources and these services depend on differing patterns of receipt between people.

While a single payment provides administrative simplicity, and might intuitively appear to achieve claimant simplicity, it can instead increase the complexity for claimants. For those who engage in complicated tasks of dividing money, received from different benefits, paid at different times for different purposes in order to successfully manage their money, Universal Credit removes these frameworks. Multiple payments can represent the least complicated option for claimants, whereas a homogenised lump sum introduces an additional money management task for some. Indeed, as study two shows, some claimants were working to establish and identify distinctions within their Universal Credit payment to create some framework for money management on a low income.

\section{Discussion}

In this article we aim to unpick the claims of simplicity that underpin the design of Universal Credit. We suggest that simplicity can be thought of as an example of policymaker common sense ('why would you not want a policy to be simple?'), which then precludes discussion of what is meant by simplicity more precisely. In policy discussions around Universal Credit, simplicity is posited both as an intrinsic good to be pursued in relation to the policy, and also as instrumental to achieving an array of other policy outcomes. Harris $(2013 ; 2015)$ has extensively documented the nature of complexity, and relatedly simplicity, in social security design; his focus is on how actors are able to navigate administrative structures and the implications of this for the nature of the social security system. We complement and extend beyond Harris' focus, by examining social security money as experienced by claimants in their daily lives.

Using the distinctions suggested by Millar (2005), we consider what is meant by simplicity in more detail by distinguishing between administrative and claimant simplicity. Crucially, simplicity needs to be defined within a given context and specific perspective, and indeed simplicity from one perspective may not translate to simplicity from another. We examine this potential disjuncture from the perspective of claimants 
in terms of Universal Credit's monthly assessments, monthly payments, and lump sum payments. We find that claims of administrative simplicity underpinning these features of Universal Credit's design are often misaligned or in conflict with what constitutes simplicity for claimants. There is a risk that overarching claims of simplicity in fact create further complexities for claimants to cope with and respond to. Complexity, in these instances in relation to managing scarce and unpredictable financial resources, is further hidden by the 'simple' design of Universal Credit, the onus is placed on claimants to cope.

Our approach highlights the importance of lived experience data when assessing how social policies operate in practice. Specifically, simplicity cannot be determined a priori, and from only one perspective. The realities of managing money on a low income are well documented (see, for example, Daly and Kelly, 2015; Patrick, 2017; Green, 2012; Hill et al, 2016; Morduch and Schneider, 2017; Pemberton et al, 2014; Shildrick et al, 2012). The findings presented in this article add to this evidence base and emphasise that this sort of experiential data must be incorporated into policy design if it is going to successfully engage with how people experience money in their own lives (practices in the Scottish social security system offer a promising model (Scottish Government, 2019)). Pushing against a potential (post)positivist bias in the evidence that is seen as legitimate to inform policy making; it is not only what can be 'counted' that 'counts'.

In sum, we argue that simplicity from the perspective of claimants for social security policy design involves a recognition that this area of policy is incredibly complicated because people's lives are complicated (Hills, 2015). Rather than considering complexity as something to be eradicated through administrative changes and reforms, a simple system from a claimant perspective is one that accounts for various complexities. In terms of the specific areas addressed in this article, this could involve giving choice over payment dates of Universal Credit in order that recipients can align this with other incomings or outgoings; and allowing claimants to choose to have payments separated out both temporally and into multiple 'pots' when delivered. As can be seen in the accounts of participants presented, the low level of social security payments, exacerbated by the initial wait for a first payment, heightens the money management challenges that claimants have to deal with. Consideration of how social security levels are set and on what basis they are determined adequate is also very relevant here. Without alterations such as these, Universal Credit is developing as a system whereby heightened responsibility is being placed on claimants to successfully manage their money and make ends meet, while at the same time claimants do not have control to better ensure that this is possible. We can frame our findings concerning simplicity and Universal Credit within broader insights about responsibilisation, where "weak and tiny units of one bear choices without resources, responsibility without power.... Responsibilised individuals are required to provide for themselves in the context of powers and contingencies that radically limit their ability to do so." (Brown, 2016; see also Donoghue and Edmiston, 2019). 


\section{Conclusion}

By questioning claims of simplicity in the case of Universal Credit, we attempt to open up an often taken-for-granted feature of policy design across multiple social and public policy contexts. Simplicity is a central tenet of how Universal Credit is designed, delivered and discussed.

A shared 'policy common sense' with regards to simplicity has accompanied Universal Credit's roll-out across the UK, from government policy documents to comments from individuals and non-governmental organisations. But looking beyond this consensus there are important clarifications and distinctions to be made. Most importantly for this article, the distinction between administrative and claimant simplicity and our evidence that demonstrates that these can conflict.

When lived experience data is taken into account, broad claims of simplicity are challenged and a policymaking process that accounts for real-world implementation is possible. Our evidence from two empirical studies shows the hardship and difficulties faced by claimants who encounter administrative rigidity while getting by on a lowincome. Their well-honed strategies, including of short-termism and earmarking, are altered and challenged by policy features characterised as administrative simplicity; claimants have few resources but increased responsibility to cope with these changes.

Where (and to who) complexity falls in the social security system is a political matter; it should be a central design consideration for Universal Credit and other social protection schemes. Simplicity of design and implementation is a vital aspect of policy discussions, but it must be clear what is meant by simplicity. Administrative simplicity must be disaggregated from claimant simplicity. The danger of not doing so is that rather than eradicating complexity for claimants, (inevitable) complexities in the social security system are further shifted out of sight and onto the shoulders of claimants themselves. 
This work was supported by the Economic and Social Research Council under Grant 1510509 and the University of Bath through a PhD studentship

The Authors declare that there is no conflict of interest.

We are very grateful to those who have provided helpful comments and suggestions for this article and related work, including the Money, Security and Social Policy Network, Jane Millar, John Hills, Hartley Dean, and attendees at the 2019 FISS and SPA conferences, as well as the two anonymous reviewers. 


\section{References}

Brown, W. (2016) Sacrificial Citizenship: Neoliberalism, Human Capital, and Austerity Politics, Constellations, 23(1): 3-14.

Centre for Social Justice (2009) Dynamic Benefits Towards welfare that works. A Policy Report from the Economic Dependency Working Group About the Centre for Social Justice, https://www.centreforsocialjustice.org.uk/core/wpcontent/uploads/2016/08/CSJ-dynamic-benefits. pdf.

Citizens Advice (2015) Waiting for Credit, http://www.boltoncab.co.uk/Global/Waiting\%20for\%20Credit\%20PDF\%20final\% 20(003)\%20Nov\%202015.pdf.

Citizens Advice (2017) Delivering on Universal Credit, https://www.citizensadvice.org.uk/Global/CitizensAdvice/welfare publications/Delivering on Universal Credit - report.pdf.

Citizens Advice (2018) Making a Universal Credit claim, https://www.citizensadvice.org.uk/Global/CitizensAdvice/welfare publications/Making a Universal Credit claim 2018 - final.pdf.

Citizens Advice (2019) Managing Money on Universal Credit, https://www.citizensadvice.org.uk/Global/CitizensAdvice/welfare publications/Managing Money on Universal Credit (FINAL).pdf.

Couling (2018) Witness Statement of Neil Couling CBE in the matter of a claim for judicial review between the Queen (on the application of) (1) Danielle Johnson (2) Claire Woods (3) Erin Barrett (4) Katie Stewart - and - Secretary of State for Work and Pensions.

Daly, M. and Kelly, G. (2015) Families and Poverty, Everyday Life on a Low Income. Bristol: Policy Press.

Davis, A., Hirsch, D., Padley, M., and Shepherd, C. (2018) A Minimum Income Standard for the UK continuity and change. York: Joseph Rowntree Foundation.

Donoghue, M. and Edmiston, D. (2019) Gritty citizens? Exploring the logic and limits of resilience in UK social policy during times of socio-material insecurity. Critical Social Policy, pp.1-23.

DWP (2010) Universal Credit: Welfare that Works. CM 7957. London: Department for Work and Pensions, https://www.gov.uk/government/uploads/system/uploads/attachment_data/file/4 8897/universal-credit-full-document.pdf.

DWP (2011) Universal Credit Policy Briefing Note 2: The payment proposal. London: Department for Work and Pensions.

DWP (2015) Universal Credit at Work, https://www.gov.uk/government/uploads/system/uploads/attachment_data/file/4 05921/uc-at-work-spring-2015.pdf.

DWP (2017) Universal Credit Test and Learn Evaluation : Families. London:

Department for Work and Pensions.

DWP (2018a) Universal Credit: different earning patterns and your payments 
(payment cycles), https://www.gov.uk/government/publications/universal-creditdifferent-earning-patterns-and-your-payments/universal-credit-different-earningpatterns-and-your-payments-payment-cycles.

DWP (2018b) Universal Credit: In-Work Progression Randomised Controlled Trial. Department for Work and Pensions, https://assets.publishing.service.gov.uk/government/uploads/system/uploads/att achment_data/file/739766/summary-universal-credit-in-work-progressionrandomised-controlled-trial.pdf.

DWP (2018c) Universal Credit Programme Full Business Case Summary. Department for Work and Pensions, https://assets.publishing.service.gov.uk/government/uploads/system/uploads/att achment_data/file/725477/uc-business-case-summary.pdf.

DWP (2019) Universal Credit and you. London: Gov.uk, https://www.gov.uk/government/publications/universal-credit-and-you/universalcredit-and-you-a\#payments----how-when-and-where.

Finch, D., Corlett, A., and Alakeson, V. (2014) Universal Credit-A policy under review, http://www.resolutionfoundation.org/wpcontent/uploads/2014/09/Universal-Credit-A-policy-under-review1.pdf.

Green, K. (2012) Life on a low income, London: Resolution Foundation.

Harris, N. (2013) Law in a Complex State: Complexity in the Law and Structure of Welfare, Oxford: Hart Publishing.

Harris, N. (2015) Complexity in the law and administration of social security: is it really a problem?, Journal of Social Welfare and Family Law, 37(2): 209-227.

Hill, K., Davis, A., Hirsch, D., and Marshall, L. (2016) Falling short: the experiences of families below the Minimum Income Standard, York: Joseph Rowntree Foundation.

Hills, J. (2015) Good Times, Bad Times, The Welfare Myth of Them and Us, Bristol: Policy Press.

Hills, J., Smithies, R., and McKnight, A. (2006) Tracking Income: How working Families' Incomes Vary through the Year, Case Report 32. ESRC Research Centre for Analysis of Social Exclusion.

Mcintosh, I. and Wright, S. (2019) Exploring what the Notion of ' Lived Experience ' Offers for Social Policy Analysis, Journal of Social Policy, 48(3): 449-467.

Millar, J. (2003) Understanding Social Security, Bristol: Policy Press.

Millar, J. (2005) Simplification, modernisation and social security, Benefits, 13: 1015.

Mirrlees, J., Adam, S., Besley, T., Blundell, R., Bond, S., Chote, R., Grammie, M., Johnson, P., Myles, G., and Poterba, J. (2011) Tax by Design. The Mirrlees Review, https://www.ifs.org.uk/publications/5353.

Monaghan, M. and Ingold, J. (2019) Policy Practitioners' Accounts of EvidenceBased Policy Making: The Case of Universal Credit, Journal of Social Policy, 
48(2): 351-368.

Morduch, J. and Schneider, R. (2017) The Financial Diaries: How American Families Cope in a World of Uncertainty, Oxford: Princeton University Press.

NAO (2018) Rolling out Universal Credit. HC 1123. Session 2017-2019. London: National Audit Office, https://www.nao.org.uk/wpcontent/uploads/2018/06/Rolling-out-Universal-Credit.pdf.

Parkhurst, J. (2017) The Politics of Evidence: From evidence-based policy to the good governance of evidence, Abingdon: Routledge.

Patrick, R. (2017) For Whose Benefit? The everyday realities of welfare reform, Bristol: Policy Press.

Pemberton, S., Fahmy, E., Sutton, E., and Bell, K. (2017) Endless Pressure: Life on a Low Income in Austere Times. Social Policy and Administration, 51(7): 11561173.

Pemberton, S., Sutton, E., Fahmy, E., and Bell, K. (2014) Poverty and Social Exclusion in the UK Life on a Low Income in Austere Times, Bristol: Poverty and Social Exclusion in the UK.

Royston, S. (2017) Broken Benefits. What's gone wrong with welfare reform, Bristol: Policy Press.

Scottish Government (2019) Social Security Experience Panels: Annual Report 2019, Scottish Government Social Research

Shildrick, T., MacDonald, R., Webster, C., and Garthwaite, K. (2012) Poverty and Insecurity, Life in low-pay, no-pay Britain, Bristol: Policy Press.

Sykes, J., Križ, K., Edin, K., and Halpern-Meekin, S. (2014) Dignity and Dreams: What the Earned Income Tax Credit (EITC) Means to Low-Income Families, American Sociological Review, 80(2): 243-267.

The Trussell Trust (2019) Five weeks is too long to wait for Universal Credit - join the campaign, https://www.trusselltrust.org/2019/02/08/five-weeks-long-waituniversal-credit-join-campaign/.

Treasury, H. (2018) The Green Book. Central Government Guidance on Appraisal and Evaluation, https://assets.publishing.service.gov.uk/government/uploads/system/uploads/att achment_data/file/685903/The_Green_Book.pdf.

Tucker, J. and Norris, D. (2018) Rough Justice. Problems with monthly assessment of pay and circumstances in universal credit, and what can be done about them, London: CPAG.

Williams (2003) The Sage Dictionary of Social Research Methods: Positivism, London: Sage.

Work and Pensions Committee (2007) Benefits Simplification. Seventh Report of Session 2006-07. Volume 1, London: The Stationary Office.

Wright, S. (2012) Welfare-to-work, Agency and Personal Responsibility. Journal of Social Policy, 41(2): 309-328. 
Wright, S. and Patrick, R. (2019) Welfare Conditionality in Lived Experience: Aggregating Qualitative Longitudinal Research. Social Policy and Society, 18(4): 597-613.

Zelizer, V.A. (2017) The Social Meaning of Money: Pin Money, Paychecks, Poor Relief, and Other Currencies, Princeton: Princeton University Press. 